\title{
Changes in the Microbiome of Cryptosporidium- Infected Mice Correlate to Differences in Susceptibility and Infection Levels
}

\author{
Raheela Charania $^{1}$, Brandy E. Wade ${ }^{1}$, Nina N. McNair ${ }^{1}$ and Jan R. Mead ${ }^{1,2, *}$ \\ 1 Department of Pediatrics, Emory University, Atlanta, GA 30033, USA; raheela.charania@emory.edu (R.C.); \\ Brandy.Wade@va.gov (B.E.W.); nmcnair@emory.edu (N.N.M.) \\ 2 Atlanta VA Medical Center, Decatur, GA 30022, USA \\ * Correspondence: jmead@emory.edu
}

Received: 14 May 2020; Accepted: 5 June 2020; Published: 10 June 2020

\begin{abstract}
Cryptosporidium spp. are opportunistic protozoan parasites that infect epithelial cells of the small intestine, causing diarrheal illness in humans. Differences in severity may be due to the immunological status of the host, malnutrition or prior exposure but may also be due to differences in the host gut flora. We examined changes in bacterial flora following antibiotic treatment to determine how cryptosporidial infections and gut integrity were affected by alterations in the microbiome. DNA was extracted from fecal and intestinal samples during peak infection. V4 region amplicons were generated and sequenced using 16sRNA on an Illumina MiSeq. Species evenness and richness were estimated using the Shannon diversity index. There was a significant decrease in anaerobes and overgrowth of Enterobacteriaceae in mice treated with cloxacillin. We also examined levels of short-chain fatty acids in fecal samples. There was a significant decrease in acetate, propionate, and butyrate in these same mice. Concurrent with the shift in bacterial infection was a significant increase in severity of cryptosporidial infection and increase in gut permeability. Treatment with other antibiotics significantly altered the microbiome but did not change the infection, suggesting that specific alterations in the host microbiome allow for more favorable growth of the parasite.
\end{abstract}

Keywords: Cryptosporidium; microbiome; short-chain fatty acid; antibiotics; cloxacillin; vancomycin

\section{Introduction}

Cryptosporidiosis can be severe and life threatening in immunocompromised individuals [1]. It is the second major cause of diarrheal illness in children globally [2] and repeated infections can lead to long-term growth deficits and cognitive impairment [3]. It is estimated that 750,000 cases in the United States of America (USA) occur annually [4]. Currently, there is no vaccine and only one drug that is Food and Drug Administration approved for immunocompetent individuals in the USA [3]. Differences in susceptibility to and severity of Cryptosporidium parvum infections have been observed but are not fully understood. These differences are likely multifactorial, including immunological status of the host, previous exposure, nutrition, and genetics. Despite the fact that Cryptosporidium is localized to the epithelium of the intestinal tract in an environment of a trillion bacteria, there have been limited studies on the effect of the gut microbiome on infection. A disrupted gut microbiome increases susceptibility to several parasitic diseases including amoebic dysentery in children [5], Giardia infections [6], and malaria [7].

Conversely, parasitic infections can lead to long-term dysbiosis of the gut [8]. In one human study, stools from C. parvum-infected volunteers showed changes in microbiota that correlated with differences in susceptibility to infection and also shifts in metabolites [9]. In mouse models of cryptosporidiosis, 
resident bacterial taxa are known to play a role in resistance. Germ-free mice are more susceptible to C. parvum infection than mice with conventional flora [10]. C. parvum is capable of triggering the development of inflammatory bowel disease (IBD)-like lesions in T cell receptor alpha (TCR- $\alpha$ ) deficient mice [11]. Interestingly, mucosal lesions are much more severe in flora-bearing TCR- $\alpha$ deficient mice compared to TCR- $\alpha$ germ-free mice [11], suggesting that certain bacteria influence the pathology of disease. Bacteria are also necessary to trigger at least one innate response through the nod-like receptor [12].

Additionally, it is not understood how the microbiome affects resistance to colonization or modulates cryptosporidial infections. Microbiome changes may occur after antibiotic or drug treatment or may be influenced by diet. Our laboratory has evaluated hundreds of drugs in vivo and found that treatment with a small but significant number of potential therapeutics and antibiotics results in increased levels (intensity) of cryptosporidial infections and may also have a significant effect on fecal microbiota [13]. The present study was undertaken to determine how changes in the microbiome affect growth of the parasite and intestinal integrity, either through changes in metabolites or alteration of key host immune responses.

\section{Materials and Methods}

\subsection{Oocyst Preparation}

C. parvum oocysts were a kind gift from Dr. Michael Arrowood (Centers for Disease Control and Prevention) and prepared as previously described [14]. Briefly, feces from experimentally infected neonatal bovine calves were passed through stainless steel sieves and oocysts purified through a series of two discontinuous Sheather's sucrose gradients (1.064 specific gravity over $1.103 \mathrm{sp}$. gr.) and a final microscale cesium chloride $(210.6 \mathrm{~g} / \mathrm{L}$, sp. gr. 1.15$)$ gradient. Oocysts were stored at $4{ }^{\circ} \mathrm{C}$ in $2.5 \%$ $(w / v)$ aqueous potassium dichromate until used. Before use, oocysts were extensively washed with phosphate-buffered saline (PBS) to remove potassium dichromate.

\subsection{Cryptosporidium Paroum Mouse Infection and Antibiotic Treatment}

All studies were conducted in accordance with Institutional Animal Care and Use Committee (IACUC) guidelines and according to the institutionally approved animal protocol (\#V016-17, approved 6/1/17). Adult IL-12 KO C57BL/6 mice were originally purchased from Jackson laboratories (Bar Harbor, ME), and subsequently bred at the Atlanta VA Medical Center animal facility. The antibiotics evaluated included cloxacillin, vancomycin-imipenem and paromomycin (a positive control that inhibits oocyst shedding by 90-95\%). Cloxacillin (TCI pharmaceuticals, Falls Church, VA, USA) and paromomycin (Sigma-Aldrich, St. Louis, MO, USA) were diluted in sterile water and administered orally at $500 \mathrm{mg} / \mathrm{kg}$ and $2000 \mathrm{mg} / \mathrm{kg}$, respectively, by daily oral gavage dosing, beginning 1 day prior to infection. Vancomycin (Geno Technology Inc., St. Louis, MO, USA), and imipenem (Biosynth International, Itasca, IL, USA) were administered in the drinking water at $0.1 \mathrm{mg} / \mathrm{mL}$, each 1 week prior to infection. Mice (8-10 weeks old) were inoculated orally with $1 \times 10^{3}$ oocysts and monitored for infection by collection of fecal pellets. Fecal pellets were collected prior to infection and at 7 days after infection (peak infection). Samples were either stored in potassium dichromate, as above, for parasite quantitation or flash-frozen and stored at $-80^{\circ} \mathrm{C}$ for DNA analysis.

Infections were assessed by quantitating the number of oocysts in the fecal pellets after concentration and purification using sucrose gradients and a flow cytometry quantitative assay $[15,16]$. Briefly, fecal samples were collected from individual mice on post-infection days 5 and 7 and processed through microscale sucrose gradients in $2.0 \mathrm{~mL}$ microcentrifuge tubes. Samples were weighed and diluent adjusted according to the weight of fecal pellets. The partially purified stool concentrate containing oocysts was incubated for $30 \mathrm{~min}$ at $37^{\circ} \mathrm{C}$ with $5 \mu \mathrm{L}$ of an oocyst-specific monoclonal antibody conjugated with fluorescein isothiocyanate (OW50-FITC), fixed with $4.0 \%$ paraformaldehyde, 
and then analyzed by means of flow cytometry. Absolute counts were calculated from the data files as oocysts per $100 \mu \mathrm{L}$ of sample suspension.

\subsection{DNA Extraction, Polymerase Chain Reaction (PCR), Sequencing, and Sequence Analysis}

Microbiome characterization was performed by Microbiome Insights Inc. (Vancouver, BC, Canada). Specimens were placed into a MoBio PowerMag Soil DNA Isolation Bead Plate. DNA was extracted following MoBio's instructions on a KingFisher robot. Bacterial 16S rRNA genes were polymerase chain reaction (PCR)-amplified with dual-barcoded primers targeting the V4 region, as per the protocol of Kozich et al. [17]. Amplicons were sequenced with an Illumina MiSeq using the 250-bp paired-end kit (v.2). Sequences were denoised, taxonomically classified using Greengenes (v. 13_8) as the reference database, and clustered into 97\%-similarity operational taxonomic units (OTUs) with the mothur software package (https://www.mothur.org/wiki/MiSeq_SOP; accessed Nov 2017) (v. 1.39.5) [18], following the recommended procedure. The potential for contamination was addressed by co-sequencing DNA amplified from specimens and from four each of template-free controls and extraction kit reagents processed the same way as the specimens. Operational taxonomic units (OTUs) were considered putative contaminants and were removed if their mean abundance in controls reached or exceeded $25 \%$ of their mean abundance in specimens.

\subsection{Bioinformatics and Statistical Analysis}

Alpha diversity and Shannon indices were determined for each experimental condition (anatomical sites, model, and antibiotic/drug treatment). Alpha diversity was estimated with the Shannon index on raw operational taxonomic units (OTUs) abundance tables after filtering out contaminants. Significance of diversity differences was tested by analysis of variance (ANOVA). Beta diversity estimates across samples excluded OTUs occurring in fewer than $10 \%$ of the samples with a count of less than three and computed Bray-Curtis indices. Beta diversity, emphasizing differences across samples, used non-metric multidimensional (NMDS) ordination. Variations in community structure were assessed with permutational multivariate analyses of variance (PERMANOVA) with treatment group as the main fixed factor using 4999 permutations for significance testing. Analyses were conducted in the R environment.

\subsection{Short-Chain Fatty Acids Determination}

Short-chain fatty acids (SCFAs) were measured by Microbiome Insights Inc. (Vancouver, BC, Canada). For this assay, fecal samples were homogenized in an aqueous solution and analyzed in a gas chromatograph coupled with a flame ionization detector using a Thermo TG-WAXMG A GC Column, $30 \mathrm{~m}, 0.32 \mathrm{~mm}, 0.25 \mu \mathrm{m}$. The method used was similar to Zhao et al., 2006 [19]. To quantify SCFAs, values for each SFCA (acetic, propionic, butyric, valeric, and heptanoic acids) were determined using a calibration curve for the concentration range of $0.015-1 \mathrm{mg} / \mathrm{mL}$.

\subsection{Gut Permeability Assay}

Intestinal permeability was determined on the day of euthanization by measuring the amount of FITC-dextran, MW 3-5 kDa (Sigma-Aldrich, St. Louis, MO, USA), in the sera $4 \mathrm{~h}$ after dosing. FITC-dextran is a marker of paracellular transport and mucosal barrier dysfunction [20]. Mice were euthanized and blood was collected from the hepatic portal vein using heparinized blood collection tubes. Blood was centrifuged at $6000 \times g, 1.5 \mathrm{~min}$. at $4^{\circ} \mathrm{C}$ and plasma was collected. Fluorescence was measured $3 \times$ for each sample in black 96-well microtiter plates using a BioTek Microplate reader with excitation at $485 \mathrm{~nm}$ and emission at $535 \mathrm{~nm}$. Concentrations were calculated from a standard curve. 


\subsection{Statistical Analysis for Parasite Load and Fluorescein Isothiocyanate (FITC)-Dextran Permeability Assay}

Statistical analyses were conducted using GraphPad Software Inc., (La Jolla, CA, USA). Differences between treatment groups and the control groups were assessed by ANOVA (mouse infection data) or by $\mathrm{T}$ test (FITC-dextran permeability assay). Median absolute deviation (MAD) method [21] along with mean plus or minus three standard deviation was used to calculate statistical outliers.

\section{Results}

\subsection{Microbiota and Infection Levels Are Altered in Response to Antibiotic Treatment}

We evaluated cloxacillin for in vivo activity, having previously demonstrated anti-cryptosporidial in vitro activity. We found that in contrast to decreasing parasite load, oral antibiotic treatment with cloxacillin significantly increased cryptosporidial infection in treated mice compared to vehicle control (Figure 1a).

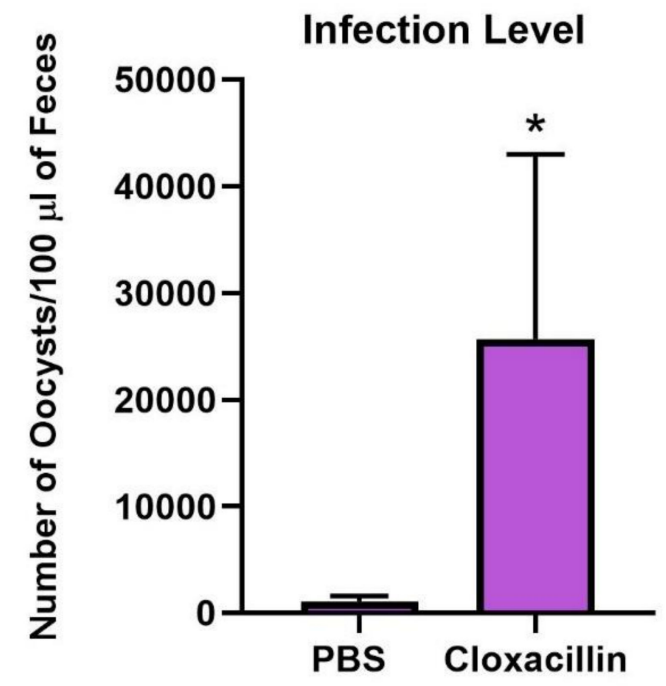

(a)

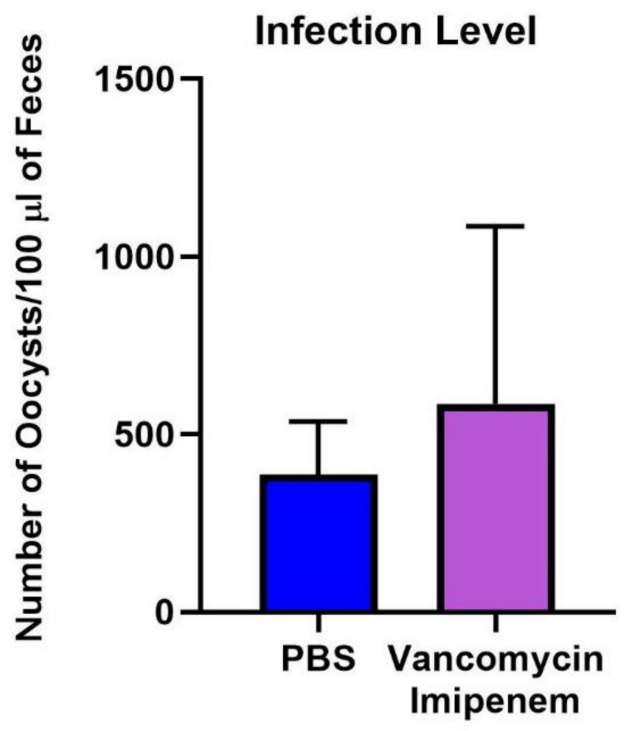

(b)

Figure 1. Parasite load in C. parvum-infected mice. Mice were infected with $10^{3}$ C. parvum oocysts and treated with either vehicle control (sterile water), cloxacillin or vancomycin-imipenem. (a) a significant increase in infection level was observed in the cloxacillin treated group ( $p<0.0019$, Mann-Whitney); (b) No significant difference was observed in mice infected with $10^{3} \mathrm{C}$. parvum oocysts and treated with vancomycin-imipenem.

One explanation for the increased infection level is that changes in flora were more favorable for parasite growth. Therefore, we examined differences in the microbiome that occurred in antibiotic treated mice that might be responsible for altered growth patterns. We found significant changes in relative abundance which were most altered in the cloxacillin treated mice compared to the uninfected controls (Figure 2). At the phylum level, in cloxacillin treated mice, there was almost a complete absence of Bacteroides (mainly consisting of anaerobes), a decrease of Firmicutes and an overgrowth of Proteobacteria. At the family level this included mainly Enterobacteriaceae (Figure 2). It should be noted that mice treated with cloxacillin displayed a distended cecum at necropsy which was slightly more severe in the infected treated group compared to the uninfected treated group. 


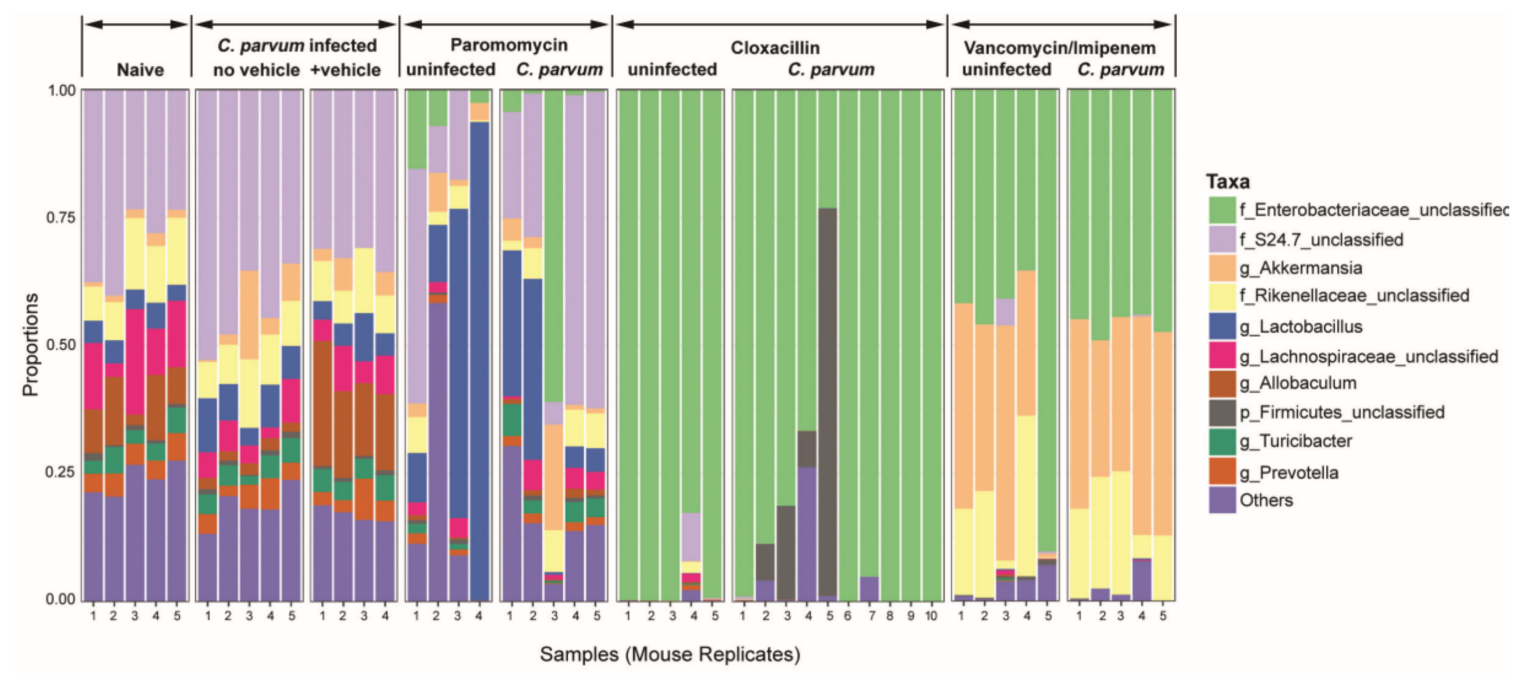

Figure 2. Differences in microbial composition of the microbiota in naïve and C. parvum infected mice including untreated and antibiotic treated groups. Relative abundances of bacterial families are shown and grouped according to their genus; bars represent individual mice within treatment groups. The antibiotics cloxacillin, vancomycin-imipenem and paromomycin disrupted the mucosal bacterial communities but only cloxacillin treatment of mice resulted in an increase in C. parvum infection. Statistically significant differences (Tukey's honest significant difference (HSD)) were observed between C. parvum infected control and cloxacillin treatment $(p<0.0005)$, and cloxacillin treatment and naive mice $(p<0.0005)$. Paromomycin treatment alters the microbiome, but the effect on the composition was less substantial than when compared to vehicle control mice $(p<0.06)$. Decreases in Allobaculum and increases in Lactobacillus, a genus known to play a role in generating short-chain fatty acids (SCFAs), were noted. Vancomycin-imipenem treatment resulted in significant changes in the composition of the microbiome. In particular, increases in Enterobacteriaceae were observed. However, there was not a complete overgrowth of Enterobacteriaceae as observed in cloxacillin-treated mice. No statistical difference was observed between the naive (uninfected) mice and C. parvum-infected mice (with or without drug diluent vehicle [sterile water]).

We examined two other antibiotics in the mouse infection model. One antibiotic, paromomycin, similar to cloxacillin, inhibits C. parvum in vitro [22]; [23] and additionally in vivo [23]. We found that paromomycin treatment alters the microbiome, resulting in decreases in Allobaculum and increases in Lactobacillus (Figure 2). No overgrowth of Enterobacteriaceae was observed. The overall bacterial load is decreased but the diversity is not impacted ( $p=0.27$ ) (Figure 3). While the microbiota is substantially altered after treatment (compared to naive, $p>0.06$ ), these specific changes do not affect the gut environment in such a way as to overcome the direct inhibition the drug has on the parasite as $>90 \%$ of the parasite is inhibited. Lastly, we also examined vancomycin-imipenem, an antibiotic combination that reportedly results in significant decreases in Gram positives and Gram negatives as well as a decrease in secondary fecal bile acids [24]. Vancomycin-imipenem also significantly altered the microbiome, resulting in increases in Enterobacteriaceae (but not a complete overgrowth as those observed in cloxacillin treated mice). Increases in Verrucomicrobia and decreases in Bacteroidetes were observed at the phylum level but impacted parasite growth only slightly (Figure 1b). Vancomycin-imipenem treatment resulted in a mean decrease of diversity $(p=0.0005)$ and a decrease in taxon among some samples (Figure 3).

In this study, C. paroum infection alone did not significantly alter flora when examined from fecal pellets (a more global assessment) (Figure 2). However, in a previous study, we found changes in flora when samples from naïve (uninfected) mice fecal pellets and infected mouse colon $(p<0.002)$ and terminal ileum were compared ( $p<0.003$, by Tukey HSD). The terminal ileum samples were more pronounced (less rich) compared to the colon which was not unexpected since the parasite infection 
is primarily located in this region. The most striking changes in mice infected with C. parvum were increased microbes belonging to the phylum Firmicutes (genera Allobaculum and Turicibacter) and decreases in the phylum Bacteroidetes (family S24.7). Thus, modest changes occur with infection in this model and were more pronounced at the local site of infection.

Species evenness was also estimated using Shannon values where a high value indicates equal distribution between species and low Shannon values suggest that certain species predominate. Significantly lower indices were found with cloxacillin treated mice when compared to vehicle control $(p<0.0005)$ (Figure 3). Decreased diversity was also observed in the vancomycin-imipenem treated mice $(p<0.0005)$, although not as severe as the cloxacillin treated mice. Shannon index was not significantly decreased for paromomycin treated mice $(p>0.27)$ or the untreated C. parvum infected group alone $(p>0.9)$ when compared to uninfected or vehicle control mice.

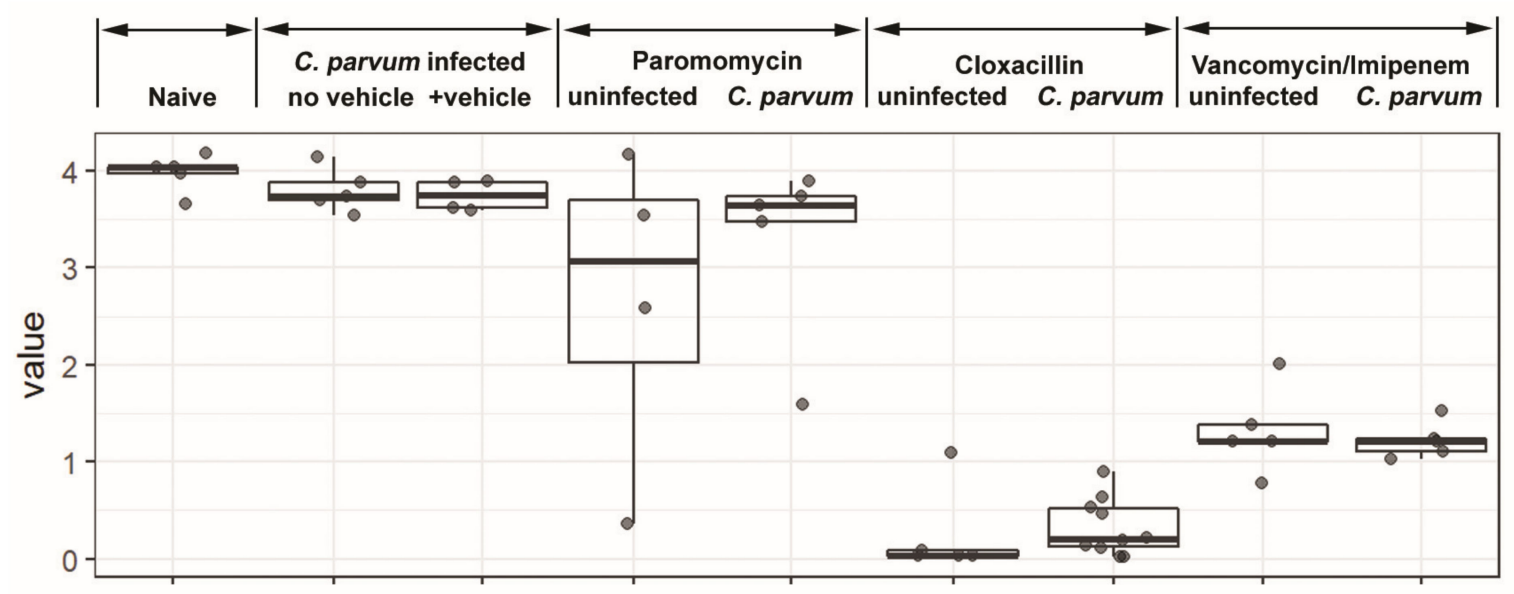

Figure 3. Box-plot comparisons of bacterial diversity and species richness. Bacterial diversity of the different groups using Shannon's alpha index. The top and the bottom boundaries of each box represent the 25th and 75th quartile values. Ends of the whisker box mark the lowest and highest diversity values in each group. Cloxacillin- and vancomycin/imipenem-treated mice had significant decreases $(p<0.0005)$ in the Shannon value. The Shannon index was not significantly decreased for paromomycin treated mice vs. vehicle controls $(p>0.27)$ or naïve $(p>0.06)$ or the untreated C. parvum infected group alone $(p>0.9)$ when compared to uninfected or vehicle control mice (determined by analysis of variance (ANOVA)).

\subsection{Gut Permeability Is Increased in Infected Mice}

In addition to short-chain fatty acids, we examined the role antibiotic treatment and infection levels had on gut permeability. We found that $C$. parvum infected mice had increased gut permeability. Serum levels of FITC-dextran were significantly increased $(p<0.008)$ in C. parvum infected mice treated with cloxacillin compared to uninfected controls (Figure 4). Cloxacillin treatment alone did not increase permeability while C. parvum infection resulted in only a modest increase (although not significantly due to the variability), suggesting that the higher parasite loads in the cloxacillin treated group contributed to decreased gut integrity.

\subsection{Short-Chain Fatty Acids Are Decreased in Antibiotic Treated Mice}

Since SCFAs are primarily generated by Gram-positive bacteria and can regulate $\mathrm{T}$ cell immune responses, we examined the changes in SCFAs in cloxacillin treated mice. Significant decreases in SCFAs were found in C. parvum infected and cloxacillin treated mice compared to C. parvum infected vehicle treated controls (Figure 5). Of the 3 major short-chain fatty acids, these included significant decreases in acetic $(60 \%$ reduction compared to control, $p=0.009)$, while butyric $(p=0.005)$ and propionic $(p=0.004)$ acids were reduced to undetectable levels (Figure 5). No significant difference 
was observed between cloxacillin treated and control groups in levels of valeric $(p=0.1)$ and hexanoic acid $(p=0.18)$.

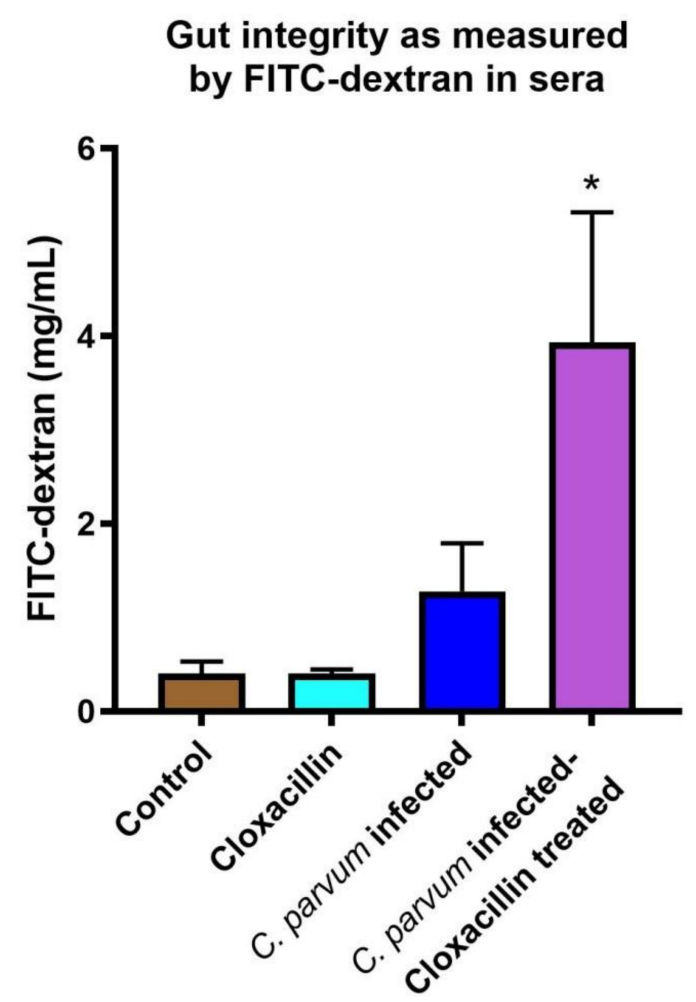

Figure 4. Permeability of the gut barrier. Serum FITC-dextran increased significantly in infected IL-12 KO mice treated with cloxacillin compared to uninfected controls $(p<0.008)$ as denoted by asterisk. Uninfected cloxacillin treated mice did not exhibit increased permeability.

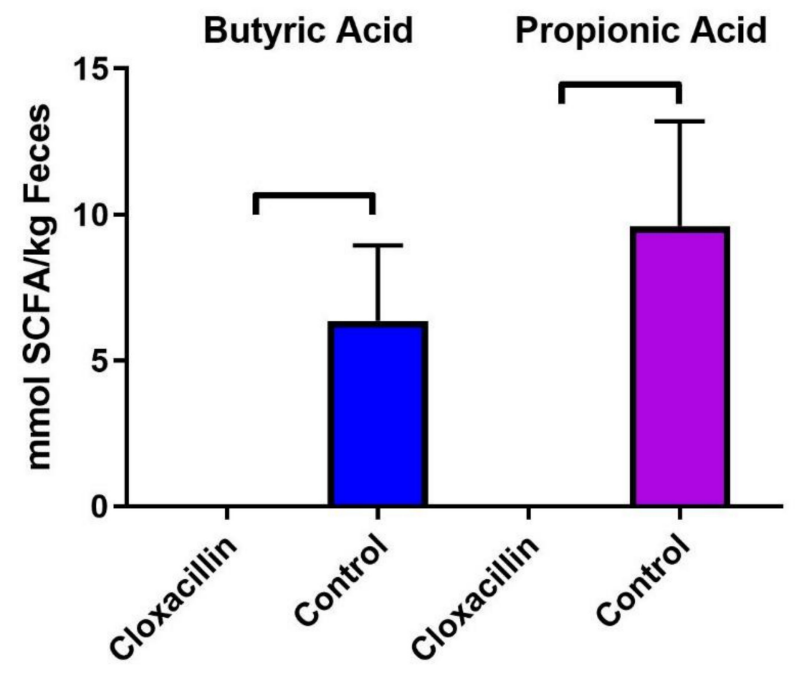

(a)

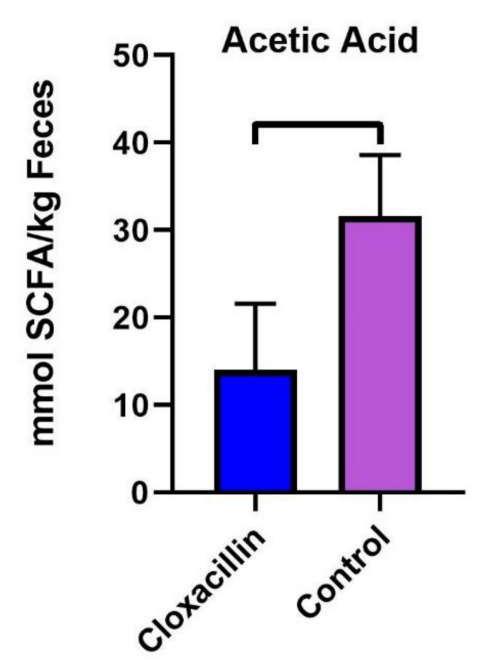

(b)

Figure 5. Short-chain fatty acids are decreased in antibiotic treated mice. Significant decreases in SCFCs were found in C. paroum infected and cloxacillin treated mice compared to C. parvum infected vehicle treated controls. These include (a) butyric $(p=0.005)$ and propionic $(p=0.004)$ acids levels below the detection limits and $(\mathbf{b})$ levels of acetic $(60 \%$ reduction compared to control, $p=0.009)$. 


\section{Discussion}

Changes in the gut flora have been described in both mice [25] and monkeys [26] following C. paroum infection. Conversely, changes in gut flora may alter the infectivity and growth of intestinal parasites. Microbiota patterns that correlated with differences in human susceptibility to cryptosporidial infection have been described in C. parvum infected volunteers [9]. These differences may be inherent or influenced by diet or ingestion of certain medications. One common cause of change in the gut microbiome is through use of antibiotics. Unfortunately, antibiotic therapy may be prescribed despite not identifying the microbial agent present and may not always be appropriate for diarrhea-causing pathogens like Cryptosporidium [27]. In fact, in some cases, inappropriate use could lead to worsening conditions.

We examined the antibiotic cloxacillin, a beta-lactamase resistant penicillin, that was first identified in an in vitro screen for fatty acyl-CoA binding protein (CpACBP1) inhibitors [28]. It has in vitro activity against $C$. parvum with an $\mathrm{EC}_{50}$ of $36 \mu \mathrm{M}$. Despite its in vitro anti-cryptosporidial activity, we observed significantly increase infections in mice. One possible explanation was that alterations in microbiota provide favorable conditions for the parasite. In particular, host commensal microbes may limit the degree of colonization, while depletion of certain populations may allow other opportunistic bacterial pathogens or commensal flora to flourish. We observed an almost complete overgrowth of Enterobacter and a depletion of Gram-positive bacteria including Clostridiales, Erysipelotrochales and Lactobacillus. Similar decreases in Clostridiales and Lactobacillus in T. gondii and Giardia muris infected C57BL/6 mice were observed while Erysipelotrochales and Enterobacter was increased in acute mouse models [29].

We also examined 2 other antibiotics: (1) a vancomycin-imipenem combination with activity against a broad spectrum of both Gram-positive and Gram-negative bacteria including Enterococcus and Pseudomonas and is reported to significantly reduce overall bacterial load [30], and (2) paromomycin, a broad spectrum aminoglycoside antibiotic that inhibits protein synthesis. A previous study reported that heavy cryptosporidial infections were associated with increased abundance of Proteobacteria [31]. While increases in Enterobacteriaceae were observed in the microbiome of vancomycin-imipenem treated mice, there was not complete overgrowth as seen with cloxacillin. Populations of Akkermansia and Rikenellaceae still remain. Consequently, infection levels were not significantly altered. Like cloxacillin, paromomycin also has activity against Cryptosporidium in vitro. In paromomycin treated mice the microbiome was significantly altered, but unlike the changes observed in the cloxacillin treated mice, bacterial alterations did not seem to change the parasite infection levels as the inherent anti-cryptosporidial activity decreased parasite load by approximately $90 \%$. While substantial decreases in the overall bacterial load were observed, no overgrowth of Enterobacter occurred and Gram-positive bacteria were still present. Gram-positive bacteria like Lactobacillus are reported to aid in maintaining the gut ecosystem and to reduce pro-inflammatory responses [32] while Clostridia species are known to play a role in generating metabolites such as butyrate, a product of fermentation [33]. Our observations would suggest that these bacteria may be important in maintaining gut homeostasis and keeping the cryptosporidial parasite in check during infection.

Little is known about metabolic changes during cryptosporidial infections and how this may impact the host immune response. C. parvum-infected human volunteers showed that at least one metabolite, indole, generated by indole-producing bacteria, was associated with susceptibility to C. parvum infection [9]. Recent attention has been focused on SCFAs that are generated primarily by Gram-positive bacteria such as Clostridia [33] by fermenting fiber. One study in mice suggested a lack of fiber may increase susceptibility to infection [31].

Concurrent with decreases in Gram-positive bacteria in cloxacillin treated mice, we observed significantly decreased levels of short-chain fatty acids. These include butyrate, propionate, and acetate, the main SCFAs produced in the gut. SCFAs have been reported to regulate the activity of $T$ reg cells and the polarization of $\mathrm{CD}^{+}{ }^{+}$into Th17 and Th1 effector cells that generate IFN- $\gamma$ [34]. IFN- $\gamma$ is an important immune factor that functions in control of cryptosporidiosis [35]. Butyrate regulates gut bacterial 
ecology while propionate upregulates NF- $\mathrm{kB}$ and IL-18 [36]. Butyrate is also a histone deacetylase inhibitor and is involved in cell cycle and cell proliferation [37]. Interestingly, butyrate, propionate and acetate are involved in upregulation of IL-18; propionate through the activation NF- $\mathrm{KB}$, butyrate through the GR109 and GR43 receptors [38] and acetate through the GR43 pathway, stimulating potassium efflux and leading to inflammasome activation [38]. IL-18 is an important immune mediator in cryptosporidiosis and decreased levels of this cytokine result in increased susceptibility and infection levels $[39,40]$. Along with the shift in microbiota diversity, C. parvum infection increased significantly (Figure 2), suggesting certain commensals (e.g., Gram positives) may function in colonization resistance either directly or through the metabolites they generate.

We also wanted to examine the effect of alterations in the microbiome and infection on gut permeability since butyrate producing bacteria are known to enhance intestinal epithelial integrity [41]. We found that cloxacillin treatment by itself had little effect on gut permeability nor did vehicle control in treated mice. However, increased Cryptosporidium infection levels in mice, due to cloxacillin treatment, significantly increased gut permeability. Subsequent studies in our laboratory with IFN- $\gamma$ $\mathrm{KO}$ mice (which have higher parasite loads than IL-12 KO mice) have demonstrated significantly increased FITC-dextran levels in sera (data not shown). Increased permeability was observed in C. parvum infected cells using transwells [42] and C. parvum infection of Caco-2 cells has been reported to decrease levels of the tight junction proteins, occludin and claudin 4 [43]. Interestingly, increased levels of indole increase epithelial integrity [44]. It may be that specific microbiota profiles lead to resistance to $C$. parvum infection and to more resilient gut integrity.

It is clear from the present study that specific alterations in the host microbiome allow for more favorable growth of cryptosporidial parasites. Whether this is through decreases in short-chain fatty acids or other metabolites that may be altered along with flora changes is still unclear. Future studies are needed to help identify the specific bacteria that may be responsible for increased resistance or susceptibility to infection.

Author Contributions: Data curation, R.C., B.E.W. and N.N.M., Formal analysis, R.C., B.E.W. and N.N.M., Funding acquisition, J.R.M., Investigation, R.C., B.E.W. and N.N.M., writing-original draft, J.R.M., writing review and editing, R.C. and B.E.W., Visualization, J.R.M., R.C. and B.E.W. Conceptualization, J.R.M., All authors have agreed to the published version of the manuscript.

Funding: This work was supported by grants from the Melissa and Bill Gates Foundation and the Foundation for Atlanta Veterans and Research.

Conflicts of Interest: The authors declare that they have no conflicts of interests. The funders had no role in the design of the study; in the collection, analyses, or interpretation of data; in the writing of the manuscript, or in the decision to publish the results.

\section{References}

1. Shirley, D.A.; Moonah, S.N.; Kotloff, K.L. Burden of disease from cryptosporidiosis. Curr. Opin. Infect. Dis. 2012, 25, 555-563. [CrossRef] [PubMed]

2. Kotloff, K.L.; Nataro, J.P.; Blackwelder, W.C.; Nasrin, D.; Farag, T.H.; Panchalingam, S.; Wu, Y.; Sow, S.O.; Sur, D.; Breiman, R.F.; et al. Burden and aetiology of diarrhoeal disease in infants and young children in developing countries (the Global Enteric Multicenter Study, GEMS): A prospective, case-control study. Lancet 2013, 382, 209-222. [CrossRef]

3. Checkley, W.; White, A.C., Jr.; Jaganath, D.; Arrowood, M.J.; Chalmers, R.M.; Chen, X.M.; Fayer, R.; Griffiths, J.K.; Guerrant, R.L.; Hedstrom, L.; et al. A review of the global burden, novel diagnostics, therapeutics, and vaccine targets for Cryptosporidium. Lancet Infect. Dis. 2015, 15, 85-94. [CrossRef]

4. Painter, J.E.; Hlavsa, M.C.; Collier, S.A.; Xiao, L.; Yoder, J.S.; Centers for Disease Control and Prevention. Cryptosporidiosis surveillance - United States, 2011-2012. MMWR Suppl. 2015, 64, 1-14. [PubMed]

5. Gilchrist, C.A.; Petri, S.E.; Schneider, B.N.; Reichman, D.J.; Jiang, N.; Begum, S.; Watanabe, K.; Jansen, C.S.; Elliott, K.P.; Burgess, S.L.; et al. Role of the gut microbiota of children in diarrhea due to the protozoan parasite Entamoeba histolytica. J. Infect. Dis. 2016, 213, 1579-1585. [CrossRef] [PubMed] 
6. Barash, N.R.; Maloney, J.G.; Singer, S.M.; Dawson, S.C. Giardia alters commensal microbial diversity throughout the murine gut. Infect. Immun. 2017, 85. [CrossRef] [PubMed]

7. Villarino, N.F.; LeCleir, G.R.; Denny, J.E.; Dearth, S.P.; Harding, C.L.; Sloan, S.S.; Gribble, J.L.; Campagna, S.R.; Wilhelm, S.W.; Schmidt, N.W. Composition of the gut microbiota modulates the severity of malaria. Proc. Natl. Acad. Sci. USA 2016, 113, 2235-2240. [CrossRef] [PubMed]

8. Partida-Rodriguez, O.; Serrano-Vazquez, A.; Nieves-Ramirez, M.E.; Moran, P.; Rojas, L.; Portillo, T.; Gonzalez, E.; Hernandez, E.; Finlay, B.B.; Ximenez, C. Human intestinal microbiota: Interaction between parasites and the host immune response. Arch. Med. Res. 2017. [CrossRef] [PubMed]

9. Chappell, C.L.; Darkoh, C.; Shimmin, L.; Farhana, N.; Kim, D.K.; Okhuysen, P.C.; Hixson, J. Fecal indole as a biomarker of susceptibility to Cryptosporidium infection. Infect. Immun. 2016, 84, 2299-2306. [CrossRef] [PubMed]

10. Harp, J.A.; Wannemuehler, M.W.; Woodmansee, D.B.; Moon, H.W. Susceptibility of germfree of antibiotic-treated adult mice to Cryptosporidium parvum. Infect. Immun. 1988, 56, 2006-2010. [CrossRef] [PubMed]

11. Sacco, R.E.; Haynes, J.S.; Harp, J.A.; Waters, W.R.; Wannemuehler, M.J. Cryptosporidium parvum initiates inflammatory bowel disease in germfree T cell receptor-alpha-deficient mice. Am. J. Pathol. 1998, 153, 1717-1722. [CrossRef]

12. Lantier, L.; Drouet, F.; Guesdon, W.; Mancassola, R.; Metton, C.; Lo-Man, R.; Werts, C.; Laurent, F.; Lacroix-Lamande, S. Poly(I:C)-induced protection of neonatal mice against intestinal Cryptosporidium parvum infection requires an additional TLR5 signal provided by the gut flora. J. Infect. Dis. 2014, 209, 457-467. [CrossRef] [PubMed]

13. Gorla, S.K.; McNair, N.N.; Yang, G.; Gao, S.; Hu, M.; Jala, V.R.; Haribabu, B.; Striepen, B.; Cuny, G.D.; Mead, J.R.; et al. Validation of IMP dehydrogenase inhibitors in a mouse model of cryptosporidiosis. Antimicrob. Agents Chemother. 2014, 58, 1603-1614. [CrossRef] [PubMed]

14. Arrowood, M.J.; Donaldson, K. Improved purification methods for calf-derived Cryptosporidium parvum oocysts using discontinuous sucrose and cesium chloride gradients. J. Eukaryot. Microbiol. 1996, 43, S89. [CrossRef] [PubMed]

15. Arrowood, M.J.; Sterling, C.R. Isolation of Cryptosporidium oocysts and sporozoites using discontinuous sucrose and isopycnic Percoll gradients. J. Parasitol. 1987, 73, 314-319. [CrossRef] [PubMed]

16. Arrowood, M.J.; Hurd, M.R.; Mead, J.R. A new method for evaluating experimental cryptosporidial parasite loads using immunofluorescent flow cytometry. J. Parasitol. 1995, 81, 404-409. [CrossRef]

17. Kozich, J.J.; Westcott, S.L.; Baxter, N.T.; Highlander, S.K.; Schloss, P.D. Development of a dual-index sequencing strategy and curation pipeline for analyzing amplicon sequence data on the MiSeq Illumina sequencing platform. Appl. Environ. Microbiol. 2013, 79, 5112-5120. [CrossRef] [PubMed]

18. Schloss, P.D.; Westcott, S.L.; Ryabin, T.; Hall, J.R.; Hartmann, M.; Hollister, E.B.; Lesniewski, R.A.; Oakley, B.B.; Parks, D.H.; Robinson, C.J.; et al. Introducing mothur: Open-source, platform-independent, community-supported software for describing and comparing microbial communities. Appl. Environ. Microbiol. 2009, 75, 7537-7541. [CrossRef] [PubMed]

19. Zhao, G.; Nyman, M.; Jonsson, J.A. Rapid determination of short-chain fatty acids in colonic contents and faeces of humans and rats by acidified water-extraction and direct-injection gas chromatography. Biomed. Chromatogr. 2006, 20, 674-682. [CrossRef] [PubMed]

20. Yan, Y.; Kolachala, V.; Dalmasso, G.; Nguyen, H.; Laroui, H.; Sitaraman, S.V.; Merlin, D. Temporal and spatial analysis of clinical and molecular parameters in dextran sodium sulfate induced colitis. PLoS ONE 2009, 4, e6073. [CrossRef] [PubMed]

21. Leys, C.; Ley, C.; Klein, O.; Bernard, P.; Licata, L. Detecting outliers: Do not use standard deviation around the mean, use absolute deviation around the median. J. Exp. Soc. Psychol. 2013, 49, 764-766. [CrossRef]

22. Marshall, R.J.; Flanigan, T.P. Paromomycin inhibits Cryptosporidium infection of a human enterocyte cell line. J. Infect. Dis. 1992, 165, 772-774. [CrossRef] [PubMed]

23. Guo, F.; Zhang, H.; Fritzler, J.M.; Rider, S.D., Jr.; Xiang, L.; McNair, N.N.; Mead, J.R.; Zhu, G. Amelioration of Cryptosporidium parvum infection in vitro and in vivo by targeting parasite fatty acyl-coenzyme A synthetases. J. Infect. Dis. 2014, 209, 1279-1287. [CrossRef] [PubMed] 
24. Vrieze, A.; Out, C.; Fuentes, S.; Jonker, L.; Reuling, I.; Kootte, R.S.; van Nood, E.; Holleman, F.; Knaapen, M.; Romijn, J.A.; et al. Impact of oral vancomycin on gut microbiota, bile acid metabolism, and insulin sensitivity. J. Hepatol. 2014, 60, 824-831. [CrossRef] [PubMed]

25. Ras, R.; Huynh, K.; Desoky, E.; Badawy, A.; Widmer, G. Perturbation of the intestinal microbiota of mice infected with Cryptosporidium parvum. Int. J. Parasitol. 2015, 45, 567-573. [CrossRef] [PubMed]

26. McKenney, E.A.; Greene, L.K.; Drea, C.M.; Yoder, A.D. Down for the count: Cryptosporidium infection depletes the gut microbiome in Coquerel's sifakas. Microb. Ecol. Health Dis. 2017, 28, 1335165. [CrossRef] [PubMed]

27. Abera, B.; Hailu, T.; Beza, L.; Mulu, W.; Yizengaw, E.; Kibret, M. Aetiology of acute diarrhoea and antimicrobial usage among children aged under five years at health centres in Bahir Dar, Ethiopia. Trop. Dr. 2020, 0049475520912558. [CrossRef] [PubMed]

28. Fritzler, J.M.; Zhu, G. Novel anti-Cryptosporidium activity of known drugs identified by high-throughput screening against parasite fatty acyl-CoA binding protein (ACBP). J. Antimicrob. Chemother. 2012, 67, 609-617. [CrossRef]

29. Craven, M.; Egan, C.E.; Dowd, S.E.; McDonough, S.P.; Dogan, B.; Denkers, E.Y.; Bowman, D.; Scherl, E.J.; Simpson, K.W. Inflammation drives dysbiosis and bacterial invasion in murine models of ileal Crohn's disease. PLoS ONE 2012, 7, e41594. [CrossRef] [PubMed]

30. Choo, J.M.; Kanno, T.; Zain, N.M.; Leong, L.E.; Abell, G.C.; Keeble, J.E.; Bruce, K.D.; Mason, A.J.; Rogers, G.B. Divergent Relationships between Fecal Microbiota and Metabolome following Distinct Antibiotic-Induced Disruptions. mSphere 2017, 2. [CrossRef] [PubMed]

31. Oliveira, B.C.M.; Widmer, G. Probiotic Product Enhances Susceptibility of Mice to Cryptosporidiosis. Appl. Environ. Microbiol. 2018, 84. [CrossRef] [PubMed]

32. Azad, M.A.K.; Sarker, M.; Li, T.; Yin, J. Probiotic species in the modulation of gut microbiota: An overview. BioMed Res. Int. 2018, 2018, 9478630. [CrossRef] [PubMed]

33. Pryde, S.E.; Duncan, S.H.; Hold, G.L.; Stewart, C.S.; Flint, H.J. The microbiology of butyrate formation in the human colon. FEMS Microbiol. Lett. 2002, 217, 133-139. [CrossRef] [PubMed]

34. Smith, P.M.; Howitt, M.R.; Panikov, N.; Michaud, M.; Gallini, C.A.; Bohlooly, Y.M.; Glickman, J.N.; Garrett, W.S. The microbial metabolites, short-chain fatty acids, regulate colonic Treg cell homeostasis. Science 2013, 341, 569-573. [CrossRef] [PubMed]

35. McDonald, V.; Korbel, D.S.; Barakat, F.M.; Choudhry, N.; Petry, F. Innate immune responses against Cryptosporidium parvum infection. Parasite Immunol. 2013, 35, 55-64. [CrossRef] [PubMed]

36. Zhang, Y.; Yu, K.; Chen, H.; Su, Y.; Zhu, W. Caecal infusion of the short-chain fatty acid propionate affects the microbiota and expression of inflammatory cytokines in the colon in a fistula pig model. Microb. Biotechnol. 2018. [CrossRef] [PubMed]

37. Mathew, O.P.; Ranganna, K.; Yatsu, F.M. Butyrate, an HDAC inhibitor, stimulates interplay between different posttranslational modifications of histone $\mathrm{H} 3$ and differently alters $\mathrm{G} 1$-specific cell cycle proteins in vascular smooth muscle cells. Biomed. Pharmacother. 2010, 64, 733-740. [CrossRef]

38. Parada Venegas, D.; De la Fuente, M.K.; Landskron, G.; Gonzalez, M.J.; Quera, R.; Dijkstra, G.; Harmsen, H.J.M.; Faber, K.N.; Hermoso, M.A. Short Chain Fatty Acids (SCFAs)-Mediated Gut Epithelial and Immune Regulation and Its Relevance for Inflammatory Bowel Diseases. Front. Immunol. 2019, 10, 277. [CrossRef]

39. Bedi, B.; McNair, N.N.; Forster, I.; Mead, J.R. Il-18 cytokine levels modulate innate immune responses and cryptosporidiosis in mice. J. Eukaryot. Microbiol. 2015, 62, 44-50. [CrossRef] [PubMed]

40. McDonald, V.; Pollok, R.C.; Dhaliwal, W.; Naik, S.; Farthing, M.J.; Bajaj-Elliott, M. A potential role for interleukin-18 in inhibition of the development of Cryptosporidium parvum. Clin. Exp. Immunol. 2006, 145, 555-562. [CrossRef]

41. Geirnaert, A.; Calatayud, M.; Grootaert, C.; Laukens, D.; Devriese, S.; Smagghe, G.; De Vos, M.; Boon, N.; Van de Wiele, T. Butyrate-producing bacteria supplemented in vitro to Crohn's disease patient microbiota increased butyrate production and enhanced intestinal epithelial barrier integrity. Sci. Rep. 2017, 7, 11450. [CrossRef] [PubMed]

42. Griffiths, J.K.; Moore, R.; Dooley, S.; Keusch, G.T.; Tzipori, S. Cryptosporidium parvum infection of Caco-2 cell monolayers induces an apical monolayer defect, selectively increases transmonolayer permeability, and causes epithelial cell death. Infect. Immun. 1994, 62, 4506-4514. [CrossRef] [PubMed] 
43. Kumar, A.; Chatterjee, I.; Anbazhagan, A.N.; Jayawardena, D.; Priyamvada, S.; Alrefai, W.A.; Sun, J.; Borthakur, A.; Dudeja, P.K. Cryptosporidium parvum disrupts intestinal epithelial barrier function via altering expression of key tight junction and adherens junction proteins. Cell. Microbiol. 2018, 20, e12830. [CrossRef] [PubMed]

44. Shimada, Y.; Kinoshita, M.; Harada, K.; Mizutani, M.; Masahata, K.; Kayama, H.; Takeda, K. Commensal bacteria-dependent indole production enhances epithelial barrier function in the colon. PLOS ONE 2013,8, e80604. [CrossRef] [PubMed]

(C) 2020 by the authors. Licensee MDPI, Basel, Switzerland. This article is an open access article distributed under the terms and conditions of the Creative Commons Attribution (CC BY) license (http://creativecommons.org/licenses/by/4.0/). 